\title{
Lung Ultrasound (LUS) and neonatal respiratory distress
}

\author{
Luigi Cattarossi \\ From 71st Congress of the Italian Society of Pediatrics. Joint National Meeting SIP, SIMGePeD, Study Group \\ on Pediatric Ultrasound, SUP Study Group on Hypertension \\ Rome, Italy. 4-6 June 2015
}

\section{Introduction}

Neonatal lung diseases are often a diagnostic dilemma for the clinician due to the low sensitivity and specificity of clinical signs and symptoms. In the last decade of the previous century the use of ultrasound in the diagnostic work-up of adult respiratory diseases became widely used $[1,2]$. The purpose of this paper is to update the knowledges on LUS in the most common neonatal respiratory diseases $[3,4]$.

\section{Materials and methods}

A high resolution linear probe $10 \mathrm{MHz}$ or more is used for lung examination. Longitudinal and transversal sections of the anterior, lateral and posterior wall are obtained. In a normal lung the pleura appears as a regular echogenic line moving during respiration. Beyond the pleura the change in acoustic impedance at the pleura-lung interface results in horizontal artifacts, defined as A-lines [5]. Vertically oriented artifacts, called B-lines, indicate an abnormality amount of fluid in the interstitial or alveolar compartment [1].

\section{Results}

Respiratory Distress Syndrome (RDS).

RDS diagnosis is based on the presence of echographic white lung without spared areas, thickened pleural line [4] . The LUS appearance immediately after administration of exogenous surfactant does not change [6].

Transient Tachypnea of the Newborn (TTN)

TTN has normal pleural line and pleural sliding, with compact B-lines in the inferior pulmonary fields and few B-lines in the superior fields [3], or bilateral "wet lung" defined as presence of numerous non-compact B-lines.

Correspondence: cattarossi.luigi@aoud.sanita.fvg.it

SOC di Patologia Neonatale. Azienda Ospedaliero Universitaria S. Maria della Misericordia. Udine-Italy
Meconium Aspiration Syndrome (MAS).

MAS shows a picture of coalescent B-lines and subpleural consolidations along with few spared areas. Subpleural consolidation distribution is irregular and may be more evident in one side.

Pneumothorax.

LUS signs of pneumothorax are absence of lung sliding, absence of B-lines and evidence of "lung point". Air between parietal and visceral pleura does not allow to see the movement of the visceral pleura on the parietal pleura and the B-lines that originate from visceral pleura, Lung point when present has a sensitivity and specificity of $100 \%$ [2]. Can be seen when the partially collapsed lung inflates and parietal and visceral pleura are in contact and lung sliding is again evident.

\section{Conclusions}

In neonatal age the use of LUS is becoming a new and reliable tool in the hand of the clinician.

LUS does not substitute chest X-ray, but can reduce its use with benefits in terms of irradiation risk [7]. The use of LUS in the clinical practice is a promising and already well established entity in neonatal age.

Published: 30 September 2015

\section{References}

1. Lichtenstein D, Mézière $G$, Biderman $P$, Gepner A, Barré O: The comet-tail artifact. An ultrasound sign of alveolar-interstitial syndrome. Am J Respir Crit Care Med 1997, 156:1640-1646.

2. Lichtenstein DA, Menu Y: A bedside ultrasound sign ruling out pneumothorax in the critically ill: lung sliding. Chest 1995, 108:1345-1348.

3. Copetti R, Cattarossi L: The "double lung point": an ultrasound sign diagnostic of transient tachypnea of the newborn. Neonatology 2007, 91:203-209.

4. Copetti R, Cattarossi L, Macagno F, Violino M, Furlan R: Lung ultrasound in respiratory distress syndrome: a useful tool for early diagnosis. Neonatology 2007, 94:52-59. 
5. Soldati G, Copetti R, Sher S: Sonographic interstitial syndrome: the sound of lung water. J Ultrasound Med 2009, 28:163-174.

6. Cattarossi L, Copetti R, Poskurica B, Miserocchi G: Surfactant administration for neonatal respiratory distress does not improve lung interstitial fluid clearance: echographic and experimental evidence. J Perinat Med 2010, 38:557-563.

7. Cattarossi L, Copetti R, Poskurica B: Radiation exposure early in life can be reduced by lung ultrasound. Chest 2011, 139:730-731.

doi:10.1186/1824-7288-41-S2-A13

Cite this article as: Cattarossi: Lung Ultrasound (LUS) and neonatal respiratory distress. Italian Journal of Pediatrics 2015 41(Suppl 2):A13.

Submit your next manuscript to BioMed Central and take full advantage of:

- Convenient online submission

- Thorough peer review

- No space constraints or color figure charges

- Immediate publication on acceptance

- Inclusion in PubMed, CAS, Scopus and Google Scholar

- Research which is freely available for redistribution

Submit your manuscript at www.biomedcentral.com/submit 